DOI: $10.5152 /$ cjms.2021.3238

Case Report

\title{
A Rare Case: Variation in The Third Part of The Axillary Artery
}

Authors: Berfu Cerci Ongun ${ }^{1-0000-0002-4016-6692}$, Ural Verimli ${ }^{2-0000-0002-4639-6990}$, Fatma Aymelek Yalın ${ }^{1-0000-0002-2438-0541}$, Suleyman Umit Sehirli ${ }^{2-0000-0001-6261-4567}$

\section{Institutions:}

${ }^{1}$ Department of Anatomy, Eastern Mediterranean University Faculty of Medicine, Famagusta, Northern Cyprus, Mersin 10, Turkey

${ }^{2}$ Department of Anatomy, Marmara University Faculty of Medicine, İstanbul, Turkey

\section{Corresponding Author: Berfu Cerci Ongun}

E-mail: berfu.ongun@emu.edu.tr

Received Date: 23.11 .2020

Accepted Date: 06.04 .2021

Cite this article as: Cerci Ongun B, Verimli U, Aymelek Yalın F, Sehirli SU. A Rare

Case: Variation in The Third Part of The Axillary Artery. Cyprus J Med Sci 2021; DOI: 10.5152/cjms.2021.3238.

This article has been accepted for publication and undergone full peer review but has not been through the copyediting, typesetting, pagination and proofreading process, which may lead to differences between this version and the Version of Record. Please cite this article as: Cerci Ongun B, Verimli U, Aymelek Yalın F, Sehirli SU. A Rare Case: Variation in The Third Part of The Axillary Artery. Cyprus J Med Sci 2021; DOI: 10.5152/cjms.2021.3238.- Available online at https://cyprusjmedsci.com/EN 


\begin{abstract}
Axillary artery branching pattern variations are commonly observed during routine dissections. These variations have a great value due to the wide range of therapeutic and diagnostic procedures carried out in the axillary region. Therefore neurovascular abnormalities should be well known before surgeries involving the axillary region to prevent complications. This case report presents a common trunk at the third part of the axillary artery that gives rise to the deep brachial artery.
\end{abstract}

Keywords: Axillary artery, common trunk, deep brachial artery, variation

\title{
Introduction
}

The anatomy knowledge of the axillary region is of great importance for neurosurgeons, orthopedic, plastic, and cardiovascular surgeons as well the radiologists. Although the variations in the axillary region are observed commonly, they are not well defined. The axillary artery is one of the structures located in this region, which requires to be studied well before any planned procedures.

Classically the subclavian artery in the neck continues as the axillary artery at the outer border of the first rib and passes through the axilla. It consists of three parts and gives six branches. The first part lies between the superior border of the pectoralis minor muscle and the first rib. It gives rise to a single branch, the superior thoracic artery, which supplies the pectoral muscles. The second part gives rise to two arteries; thoraco-acromial and lateral thoracic artery, and it is located posterior to the pectoralis minor muscle. These two arteries provide blood This article has been accepted for publication and undergone full peer review but has not been through the copyediting, typesetting, pagination and proofreading process, which may lead to differences between this version and the Version of Record. Please cite this article as: Cerci Ongun B, Verimli U, Aymelek Yalın F, Sehirli SU. A Rare Case: Variation in The Third Part of The Axillary Artery. Cyprus J Med Sci 2021; 
supply to the pectoral muscles, the skin around that region, and the axillary lymph nodes. Finally, the third part lies inferior to the pectoralis minor muscle and gives three branches. The first and the largest artery that arises from the third part is the subscapular artery, supplying the skin and the muscles of the shoulder and the thoracic wall. The other two arteries rising from the third part are the posterior and the anterior humeral circumflex arteries. The surgical neck of humerus will be wrapped with these two arteries that supply the shoulder joint. The axillary artery continues its course and becomes the brachial artery right after exiting the axilla, at the inferior border of the teres major muscle. The deep brachial artery is the largest branch of the brachial artery, and it arises below the inferior border of the teres major muscle $(1,2)$.

\section{Case Presentation}

During the routine dissection for educational purposes, a variation was noticed in the branching pattern of the third part of the axillary artery. The variation was observed on the left axillary region of a male cadaver aged 63 . To view the axillary artery clearly, the skin and the fascia were removed, and the pectoralis major muscle was retracted. Median and musculocutaneous nerves were detected and pulled away with clamps in order to view all branches of the axillary artery. The branching pattern of the first and the second parts of the axillary artery was observed as normal. A common trunk was observed just below the subscapular artery at the third part of the axillary artery. This common trunk gave branches to anterior and posterior humeral circumflex arteries, brachial artery, and deep brachial artery (Figure 1). Further branching pattern and the course of the deep brachial artery were noted as regular, and no additional abnormalities were detected.

\section{Discussion}

This article has been accepted for publication and undergone full peer review but has not been through the copyediting, typesetting, pagination and proofreading process, which may lead to differences between this version and the Version of Record. Please cite this article as: Cerci Ongun B, Verimli U, Aymelek Yalın F, Sehirli SU. A Rare Case: Variation in The Third Part of The Axillary Artery. Cyprus J Med Sci 2021; 
Variations located in the axillary region, especially the axillary artery branching pattern, are frequently observed either during cadaveric dissections or clinical cases. A study conducted with 40 cadavers showed that the variant pattern of the axillary artery was $63 \%$ in males and $58 \%$ in women (3). Variation similar to our case has been reported; the common trunk at the third part of the axillary artery gave branches to anterior and posterior circumflex humeral, ulnar collateral arteries, and deep brachial artery at the same time (4). Another interesting case of axillary artery variation was published where the medial and lateral roots of the median nerve sandwiched the abnormal common trunk (5). An unusual variation at the third part of the axillary artery was published in 2017, where a common trunk gave branches to the lateral thoracic artery and continued as posterior circumflex humeral artery (6).

Knowledge of the axillary artery branching pattern is vital for surgeons while treating axillary artery thrombosis, attending to axillary region traumas, and cannulating the axillary artery (7). The right axillary artery can be used for cannulation as another option to femoral artery cannulation, especially in patients suffering from iliofemoral arterial occlusion (8). Axillary lymph node dissection is commonly performed as a part of the surgical treatment of breast cancer patients, and this procedure is also being used to determine the stage and the management of breast cancer. Any variation in the course of the vessels located in the axillary region must be well identified when planning the procedure(9). Radiological and surgical reviewing of the region can prevent complications that could occur during procedures scheduled in the axillary region. Therefore the anatomical knowledge of the variations of the region is vital for surgeons and radiologists.

This article has been accepted for publication and undergone full peer review but has not been through the copyediting, typesetting, pagination and proofreading process, which may lead to differences between this version and the Version of Record. Please cite this article as: Cerci Ongun B, Verimli U, Aymelek Yalın F, Sehirli SU. A Rare Case: Variation in The Third Part of The Axillary Artery. Cyprus J Med Sci 2021; 


\section{References}

1. Starding S. Gray’s Anatomy The Anatomical Basis of Clinical Practice. 41st ed. Elsevier; 2016. 2250 p.

2. Huelke DF. Variation in the origins of the branches of the axillary artery. Anat Rec. $1959 ; 135(1): 33-41$.

3. Astik R, Dave U. Variations in branching pattern of the axillary artery: a study in 40 human cadavers. J Vasc Bras. 2012;11(1):12-7.

4. Ramificaci D, De A, Axilar A, Cl S. Abnormal Branching Pattern of the Axillary Artery. 2008;26(2):389-92.

5. George BM, Nayak S, Kumar P. Clinically significant neurovascular variations in the axilla and the arm - A case report. Neuroanatomy. 2007;6(January):36-8.

6. Banerjee A, Kumari C, Jhajhria SK. Variation in the branching pattern of third part of axillary artery-A case report. J Clin Diagnostic Res. 2017;11(2):AD03-4.

7. Sabik JF, Lytle BW, McCarthy PM, Cosgrove DM. Axillary artery: An alternative site of arterial cannulation for patients with extensive aortic and peripheral vascular disease. J Thorac Cardiovasc Surg. 1995;109(5):885-91.

8. Siminelakis SN, Baikoussis NG, Papadopoulos GS, Beis IP. Axillary artery cannulation for cardiopulmonary bypass during surgery on the ascending aorta and arch. J Card Surg. 2009;24(3):301-4.

9. Soares EWS. Anatomical variations of the axilla. Springerplus. 2014;3(1):1-7. 
Figure Legends:

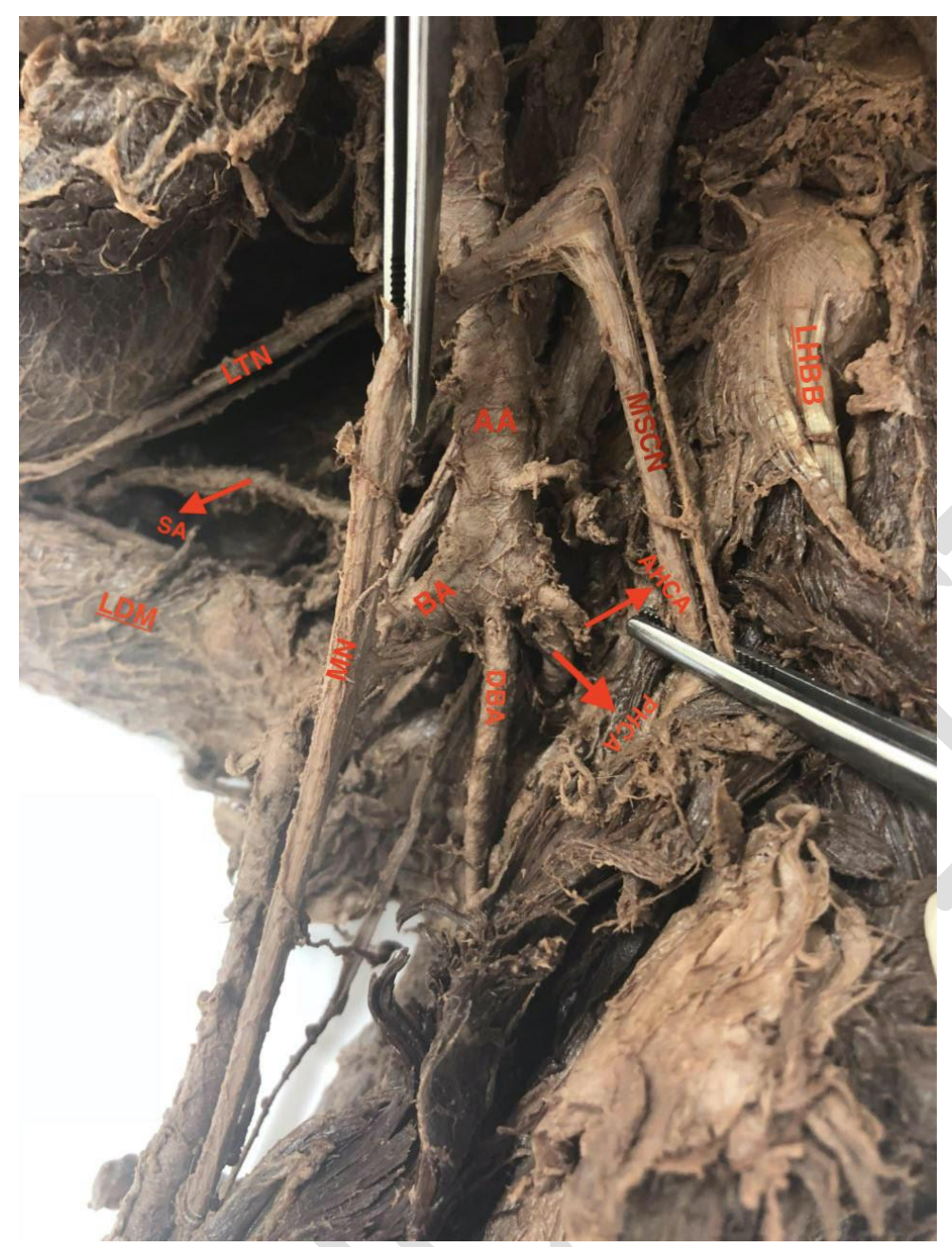

\section{Figure 1.}

This article has been accepted for publication and undergone full peer review but has not been through the copyediting, typesetting, pagination and proofreading process, which may lead to differences between this version and the Version of Record. Please cite this article as: Cerci Ongun B, Verimli U, Aymelek Yalın F, Sehirli SU. A Rare Case: Variation in The Third Part of The Axillary Artery. Cyprus J Med Sci 2021; DOI: 10.5152/cjms.2021.3238.- Available online at https://cyprusjmedsci.com/EN 